\title{
Tendon end separation with loading in an Achilles tendon repair model: comparison of non-absorbable vs. absorbable sutures
}

\author{
Michael R. Carmont ${ }^{1,4^{*}}$, Jan Herman Kuiper ${ }^{2}$, Karin Grävare Silbernagel ${ }^{3}$, Jón Karlsson ${ }^{4}$ \\ and Katarina Nilsson-Helander ${ }^{4,5}$
}

\begin{abstract}
Background: Rupture of the Achilles tendon often leads to long-term morbidity, particularly calf weakness associated with tendon elongation. Operative repair of Achilles tendon ruptures leads to reduced tendon elongation. Tendon lengthening is a key problem in the restoration of function following Achilles tendon rupture. A study was performed to determine differences in initial separation, strength and failure characteristics of differing sutures and numbers of core strands in a percutaneous Achilles tendon repair model in response to initial loading.
\end{abstract}

Methods: Nineteen bovine Achilles tendons were repaired using a percutaneous/minimally invasive technique with a combination of a modified Bunnell suture proximally and a Kessler suture distally, using non-absorbable 4-strand 6strand repairs and absorbable 8-strand sutures. Specimens were then cyclically loaded using phases of 10 cycles of $100 \mathrm{~N}, 100$ cycles of $100 \mathrm{~N}, 100$ cycles of $190 \mathrm{~N}$ consistent with early range of motion training and weight-bearing, before being loaded to failure.

Results: Pre-conditioning of 10 cycles of $100 \mathrm{~N}$ resulted in separations of $4 \mathrm{~mm}$ for 6-strand, $5.9 \mathrm{~mm}$ for 4-strand, but $11.5 \mathrm{~mm}$ in 8-strand repairs, this comprised 48.5, 68.6 and $72.7 \%$ of the separation that occurred after 100 cycles of $100 \mathrm{~N}$. The tendon separation after the third phase of 100 cycles of $190 \mathrm{~N}$ was $17.4 \mathrm{~mm}$ for 4-strand repairs, $16.6 \mathrm{~mm}$ for 6-strand repairs and $26.6 \mathrm{~mm}$ for 8-strand repairs. There were significant differences between the groups $(p<0$. 0001). Four and six strand non-absorbable repairs had significantly less separation than 8-strand absorbable repairs ( $p=0.017$ and $p=0.04$ respectively).

The mean (SEM) ultimate tensile strengths were 4-strand $464.8 \mathrm{~N}(27.4), 6$-strand $543.5 \mathrm{~N}(49.6)$ and 8-strand $422.1 \mathrm{~N}$ (80.5). Regression analysis reveals no significant difference between the overall strength of the 3 repair models ( $p=0$. 32) (4 vs. 6: $p=0.30,4$ vs. 8: $p=0.87 ; 6$ vs. 8: $p=0.39$ ). The most common mode of failure was pull out of the Kessler suture from the distal stump in $41.7 \%$ of specimens.

Conclusion: The use of a non-absorbable suture resulted in less end-to-end separation when compared to absorbable sutures when an Achilles tendon repair model was subject to cyclical loading. Ultimate failure occurred more commonly at the distal Kessler suture end although this occurred with separations in excess of clinical failure. The effect of early movement and loading on the Achilles tendon is not fully understood and requires more research.

Keywords: Tendon rupture, Suture, Biomechanical

\footnotetext{
* Correspondence: mcarmont@hotmail.com

'Department of Orthopaedic Surgery, Princess Royal Hospital, Shrewsbury \&

Telford Hospital, Telford, UK

${ }^{4}$ Department of Orthopaedic Surgery, Sahlgrenska Academy, University of

Gothenburg, Gothenburg, Sweden

Full list of author information is available at the end of the article
} 


\section{Background}

Rupture of the Achilles tendon leads to long-term morbidity, particularly 10-30\% calf weakness (Barfod et al., 2017; Horstmann et al., 2012; Lantto et al., 2015; Mavrodontidis et al., 2015). This weakness has been associated with tendon elongation (Silbernagel et al., 2012). Operative repair of Achilles tendon ruptures leads to improved early outcome (Keating \& Will, 2011), in terms of strength (Lantto et al., 2016; Willits et al., 2010) and functional activities (Olsson et al., 2011; Olsson et al., 2014) and reduced tendon elongation of $18.7 \mathrm{~mm}$ compared to non-operative treatment $(P<0.01)$ (Heikkinen et al., 2017) although lengthening ( $5 \mathrm{~mm}$ at 12 months, and $14.5 \mathrm{~mm}$ at 13 years) still occurs even in augmented repairs (Heikkinen et al., 2016; Pajala et al., 2009).

Minimally invasive and percutaneous surgery for the Achilles tendon rupture aims to provide a stable repair, allowing early weight-bearing and movement, whilst minimizing the risks of wound breakdown or infection (Del Buono et al., 2014; Khan \& Carey Smith, 2010; McMahon et al., 2011; Yang et al., 2017) (Figs. 1a. Biomechanical comparison has shown that the $\mathrm{Ma}$ and Griffiths percutaneous technique (Ma \& Grifith, 1977) has approximately $50 \%$ of the strength of open repairs and has an increased iatrogenic nerve injury rate (Chan et al., 2011; Del Buono et al., 2014; Hockenbury \& Johns, 1990) although this has been reduced using of absorbable sutures and visualization and protection of the nerve during surgery (Klein et al., 1991).

The use of a combined modified Bunnell and Kessler suture configuration (Carmont \& Maffulli, 2008) (Fig. 1b) using an absorbable monofilament suture shows good clinical outcome (Al-Mouazzen et al., 2005; Carmont et al., 2013) as well as specific patient subsets; athletes (Maffulli et al., 2011b), the elderly (Maffulli et al., 2010) and diabetic patients (Maffulli et al., 2011c). This suture technique has similar repair strength to that of the box suture formed using the Achillon device (Longo et al., 2012).

Although monofilament absorbable sutures e.g. polyglyconate co-polymer Maxon (Covidien, Mansfield, MA, USA) are broken down over 6 weeks, which may potentially avoid stress shielding (Table 1), the associated inflammatory response may actually weaken the healing tendon predisposing to re-rupture at a key phase in the rehabilitation process. Braided non-absorbable sutures made from polyester coated with a polytetrafluoroethylene (PTFE) layer (Fiberwire ${ }^{\oplus}$, Arthrex, Naples, USA) are commonly used for Achilles tendon repair (De La Fuente et al., 2016a; Hsu et al., 2015; Keller et al., 2014). The sutures offer the advantages of strength, smooth passage through the tendon and secure knots (Benthien et al., 2006). An increased number of core suture strands has been shown to increase the strength of suture repair models (Backus et al., 2017; Ortiz et al., 2012) but this has not been studied using the combined modified Bunnell and Kessler configuration.

The aim of this biomechanical study was to determine differences in initial separation, strength and failure characteristics of differing sutures and numbers of core strands in a percutaneous Achilles tendon repair model. The null hypothesis was that there would be no difference in tendon separation between repairs when subject to cyclical loading.
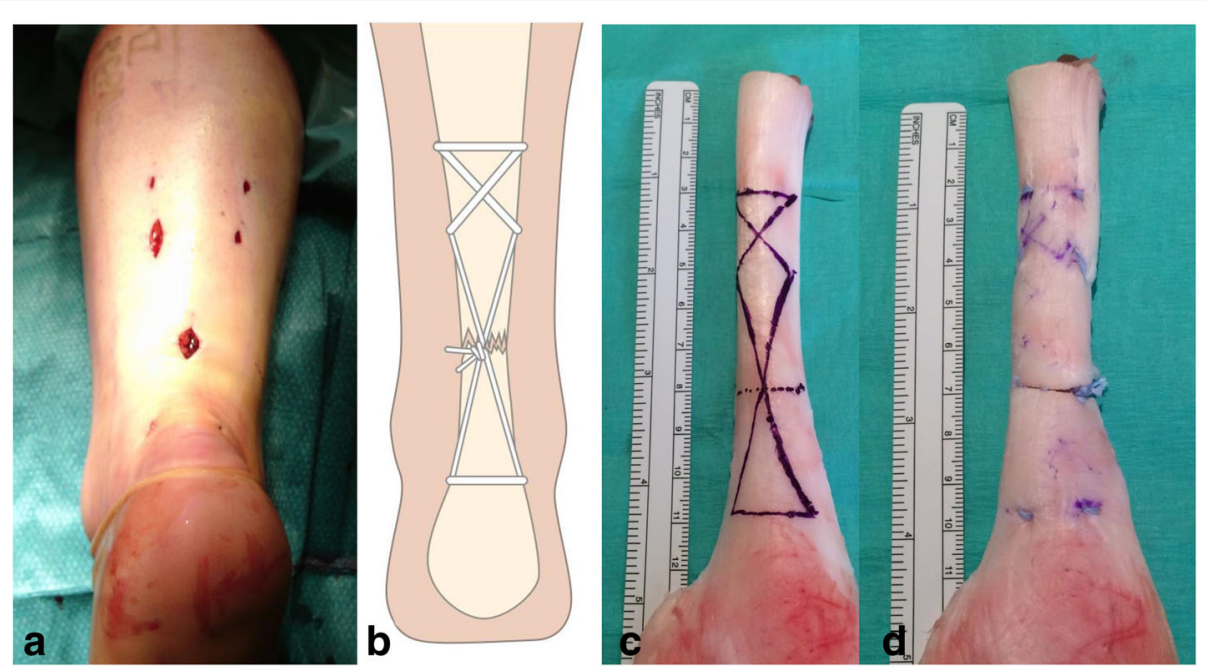

Fig. 1 a The cosmetic and wound size of minimally invasive repair prior to skin closure, $\mathbf{b}$ a schematic of repair performed using the combination of a modified Bunnell suture proximally and a Kessler suture distally. c Bovine flexor tendon following dissection of the fascia and paratenon layers. $\mathbf{d}$ The final testing specimen of an Achilles tendon repair model. Note the end-to-end tendon apposition 
Table 1 Characteristics of Fiberwire and Maxon sutures

\begin{tabular}{|c|c|c|}
\hline Suture Configuration & Fiberwire $^{\oplus}$ & Maxon $^{\oplus}$ \\
\hline Size USP & 2 & 1 \\
\hline $\begin{array}{l}\text { Single strand } \\
\text { diameter/mm }\end{array}$ & 0.5 & 0.4 \\
\hline $\begin{array}{l}\text { Mass suture Cross } \\
\text { Sectional Area/mm² }\end{array}$ & $\begin{array}{l}\text { 4-strand }=0.54 \\
6 \text {-strand }=0.8\end{array}$ & 8 -strand $=0.69$ \\
\hline Material & $\begin{array}{l}\text { Polytetrafluoroethylene } \\
\text { (PTFE) coated polyester }\end{array}$ & $\begin{array}{l}\text { Polyglyconate co- } \\
\text { polymer of glycolic } \\
\text { acid and Trimethylene } \\
\text { Carbonate }\end{array}$ \\
\hline Thread type & Braided & Mono-filament \\
\hline Colour & Blue & Green \\
\hline Absorption & Non-absorbable & $\begin{array}{l}\text { Absorbable predictable } \\
180 \text { days }\end{array}$ \\
\hline $\begin{array}{l}\text { Ultimate tensile } \\
\text { strength single } \\
\text { strand }\end{array}$ & $345 N$ & $\begin{array}{l}54 \mathrm{~N} \\
\text { Strength profile: } \\
80 \% \text { at } 1 \text { week } \\
75 \% \text { at } 2 \text { weeks } \\
65 \% \text { at } 3 \text { weeks } \\
50 \% \text { at } 4 \text { weeks } \\
25 \% \text { at } 6 \text { weeks }\end{array}$ \\
\hline
\end{tabular}

\section{Methods}

Prior to commencing the study, approval was obtained from the Robert Jones and Agnes Hunt Hospital Research and Development Department (RL1 620 IRAS 173197). All specimens were obtained from local abattoirs from juvenile animals (2 years old) slaughtered for human consumption. Pilot testing was performed using 5 ovine tendons and 5 bovine tendons. This determined that ovine tendons were too small to insert the suture materials in the in vivo configuration and as a result bovine tendons were used. Subsequent testing of bovine tendons permitted consistent repairs to be made to allow cyclical loading to ultimate tensile failure and minimize clamp pull out. Bovine tendons have previously been successfully used to provide specimens to represent human Achilles tendons for biomechanical studies (Benthien et al., 2006; De La Fuente et al., 2016b; Guzzini et al., 2017; Ortiz et al., 2012).

\section{Specimen preparation}

Nineteen fresh frozen lower limb flexor tendons were prepared following thawing in a refrigerator. The flexor tendon specimens were resected proximal to the musculotendinous junction and the collateral insertional slips from either side of the calcaneus. The layers of the fascia and the paratenon were removed and the distal muscle bulk was resected off the septum. The mid-substance flexor tendon specimen sample was typically 10-12 cm in length. The thinnest section of the tendon was marked with a transverse line using a surgical marking pen for the tenotomy mean (SD) thickness antero- posterior (AP) was $13.6 \mathrm{~mm}$ (1.6) (range 10.8-17.0 mm), transverse thickness using a vernier caliper and the cross sectional area determined as $196.5 \mathrm{~mm}^{2}$ (30.4) (range 131.97-245.9) using the formula:

$$
\text { Area }=\pi \bullet \mathrm{AP} \text { radius } \bullet \text { Transverse radius. }
$$

Additional transverse marks, at $3 \mathrm{~cm}$ and $5 \mathrm{~cm}$ proximally and another mark at $3 \mathrm{~cm}$ distally to the tenotomy line indicated the transverse and oblique lines of suture passage (Fig. 1c). A number 10 scalpel was then used to make a transverse tenotomy representing the rupture site. The insertion point into both side of the calcaneus in the bovine specimens made it difficult to measure corresponding a typical rupture site 4-6 cm proximal to the insertion as in humans so the tenotomy was made at the thinnest part of the tendon.

A $9 \mathrm{~cm} \mathrm{B204/00} \mathrm{curved} \mathrm{needle} \mathrm{with} \mathrm{a} \mathrm{cutting} \mathrm{tip} \mathrm{was}$ used for all suture passes (Acufirm, Ernst Kratz $\mathrm{GmbH}$ ), threaded with 2, 3 or 4 sutures. A modified Bunnell suture was inserted through the proximal tendon $5 \mathrm{~cm}$ from the tenotomy, approximately a $3 \mathrm{~mm}$ distance was maintained between the site of the emerging needle and the position of re-insertion. Distally, a Kessler suture was formed by transversely passing the passing the needle at $3 \mathrm{~cm}$ distal to the tenotomy (Fig. 1c \& d). Sutures from either end of the tendon were then tied, en mass, using a double throw surgeons knot and 4 subsequent hitches as tight as possible with the aim of apposing the part of the tenotomised tendon ends despite the interposed suture knots (Fig. 1d).

The tendon ends were then compressed in a vice and wrapped in course sandpaper mesh before being loaded into the clamp and tightened. An initial tension of $10 \mathrm{~N}$ was applied using a testing machine and the anteroposterior diameter and transverse diameter of the tendon measured using a vernier caliper, in millimeters to two decimal places (Digitromic Caliper, Design Line Series, Moore \& Wright, UK). These measurements were repeated several times until a consistent value was obtained. If apposition of the tendon ends occurred, separation was determined as zero, otherwise the initial separation was measured using the caliper. This same position on the tendon was used for all subsequent separation measurements.

Specimens were tested in random order to allow for optimization of surgical technique. In Group 1, 6 specimens were prepared using 4-strand Fiberwire sutures. In Group 2, 7 specimens were repaired using 6strand Fiberwire sutures. Finally 6 specimens were repaired using 8-strand Maxon sutures. These suture numbers and combinations were chosen as they have been used in standard practice (Carmont et al., 2013; Carmont et al., 2015; Carmont et al., 2017). There was no significant 
difference in cross sectional area between the groups $(p=0.247)$.

\section{Loading protocol}

Tendon specimens were subject to a cyclical loading programme, using a hydraulic biomechanical testing machine (ESH, Brierley Hill, UK) and the output sampled using an analogue to digital converter connected to a laboratory computer (Fig. 2). This programme has been chosen as it has been used in testing Achilles tendon repair models to represent the early stages of rehabilitation (Akizuki et al., 2001; Demetracopoulos et al., 2014; Lee et al., 2009): passive ankle range of motion $(100 \mathrm{~N})$ and walking in a controlled ankle motion walking boot with a $2.5 \mathrm{~cm}$ heel lift $(190 \mathrm{~N})$. The present study included 4 phases of cyclical loading:

1. "Pre-conditioning" with 10 cycles at $100 \mathrm{~N}$ at frequency $1 \mathrm{~Hz}$.

2. An additional sequence of 90 cycles at $100 \mathrm{~N}$.

3. A further 100 cycles at $190 \mathrm{~N}$.

4. Finally the tendon was loaded until complete failure.

After each phase of loading the separation of the tendon ends was measured using the vernier caliper (Ortiz et al., 2012). Clinical failure was considered to be an end-to-end separation of greater or equal to $20 \mathrm{~mm}$,

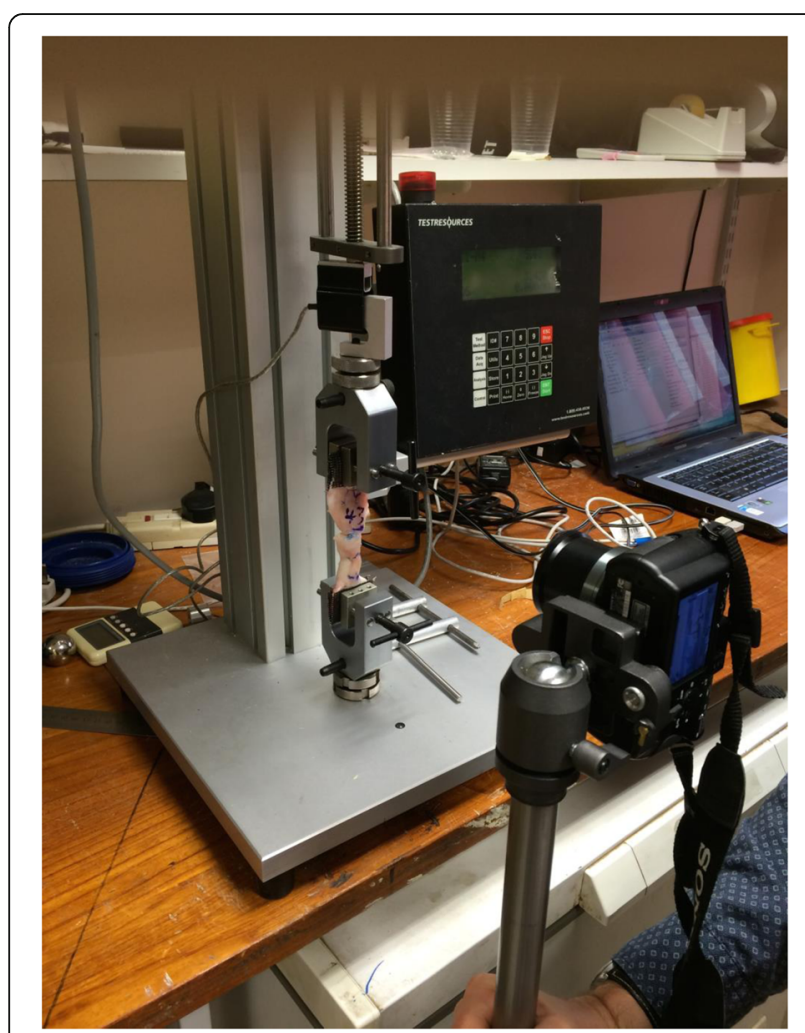

Fig. 2 The biomechanical testing jig and experimental set up comparable to elongation noted in non-operative management (Heikkinen et al., 2017). If a phase of loading could not be completed the number of cycles that were completed before failure was noted.

Additionally the mode of failure of each repair model was noted. Cyclical loading of the tendon was digitally recorded using a camera to determine the specific characteristics and pattern of the loading and failure of the tendon repair model.

\section{Statistical analysis}

A sample size of six $(n=6)$ is the standard sample size recommended for fatigue testing (ASTM E739-91, 1998). This was consistent with group sample numbers for other Achilles tendon biomechanical studies: Demetracopoulos $n=7$, Lee $n=5$, Longo $n=9$, Ortiz $n=5$ ) (Demetracopoulos et al., 2014; Lee et al., 2009; Longo et al., 2012; Ortiz et al., 2012).

Separation measurements between groups over the 4 phases of the loading protocol were compared using one-way ANOVA. Censored regression analysis was performed to evaluate ultimate failure to account for specimen pull out from the jig. Data was analyzed using SPSS Version 24. A level of significance of $p<0.05$ was chosen.

\section{Results}

In $79 \%$ of specimens the suture configuration permitted end-to-end tendon apposition when positioned on the testing jig and subjected to an initial load of $10 \mathrm{~N}$ (Table 2). Two specimens in each of the 4-strand and 8-strand groups had initial separation rather than apposition due to the interposed knots between the tendon ends. Only one specimen in the 6-strand group did not have initial end-toend apposition, however, this was the largest at $3.9 \mathrm{~mm}$ separation.

Pre-conditioning of 10 cycles of $100 \mathrm{~N}$ resulted in separations of $4 \mathrm{~mm}$ for 6-strand, $5.9 \mathrm{~mm}$ for 4-strand but $11.5 \mathrm{~mm}$ in 8-strand repairs, this comprised 48.5, 68.6 and $72.7 \%$ of the separation that occurred after $100 \mathrm{cy}$ cles of $100 \mathrm{~N}$ (Fig. 3).

The tendon separation after the third phase of 100 cycles of $190 \mathrm{~N}$ was $17.4 \mathrm{~mm}$ for 4-strand repairs, $16.6 \mathrm{~mm}$ for 6-strand repairs and $26.6 \mathrm{~mm}$ for 8-strand repairs. Over the four phases of the loading programme there was a significant difference between the different repairs $(p<0.0001)$. Four and six strand non-absorbable repairs had significantly less separation than 8-strand absorbable repairs ( $p=0.017$ and $p=0.04$ respectively). There were no significant differences between the 4 and 6 strand repairs $(p=1)$. When clinical failure was considered to be tendon end separation of $\geq 20 \mathrm{~mm}$ all of the 8-strand repairs failed, whereas only one of the 4-strand specimens and none of the 6 -strand specimens failed. 
Table 2 The separations of the Achilles tendon repair models with the 4 phases of loading, and the mode of failure

\begin{tabular}{|c|c|c|c|c|c|c|c|c|}
\hline $\begin{array}{l}\text { Specimen } \\
\text { number }\end{array}$ & Strand & $\begin{array}{l}\text { XSectional } \\
\text { Area/mm }{ }^{2}\end{array}$ & $\begin{array}{l}\text { Initial Separation } \\
(10 \mathrm{~N}) / \mathrm{mm}\end{array}$ & $\begin{array}{l}\text { Separation } \\
(10 \text { cycles } \\
100 \mathrm{~N}) / \mathrm{mm}\end{array}$ & $\begin{array}{l}\text { Separation }(100 \\
\text { cycles } 100 \mathrm{~N}) / \mathrm{mm}\end{array}$ & $\begin{array}{l}\text { Separation (100 } \\
\text { cycles } 190 \mathrm{~N}) / \mathrm{mm}\end{array}$ & $\begin{array}{l}\text { Ultimate Tensile } \\
\text { Failure/N }\end{array}$ & Mode of Failure \\
\hline 1 & 4 & 143.3 & 2.9 & 6.8 & 10.3 & 20.5 & 241 & Pull out jig \\
\hline 2 & 4 & 170.5 & 0 & 6.7 & 9.3 & 17.0 & 405 & Distal pull out \\
\hline 3 & 4 & 192.8 & 0 & 3.1 & 5.3 & 15.4 & 399 & Knot Failure \\
\hline 4 & 4 & 222.3 & 0 & 7.1 & 10.2 & 19.6 & 411 & Pull out jig \\
\hline 5 & 4 & 166.3 & 3.0 & 6.0 & 8.6 & 16.6 & 464 & Suture snap \\
\hline 6 & 4 & 188.3 & 0 & 5.6 & 7.4 & 15.3 & 508 & Distal pull out \\
\hline Mean(SD) & & & $1.0(1.5)$ & $5.9(1.5)$ & $8.5(1.9)$ & $17.4(2.2)$ & $465(27)$ & \\
\hline 1 & 6 & 221.4 & 3.9 & 7.7 & 13.7 & 23.5 & 321 & Pull out jig \\
\hline 2 & 6 & 131.9 & 0 & 2.6 & 5.4 & 12.8 & 419 & Proximal pull out \\
\hline 3 & 6 & 245.9 & 0 & 2.5 & 3.4 & 9.4 & 462 & Pull out jig \\
\hline 4 & 6 & 173.8 & 0 & 5.4 & 8.7 & 17.7 & 567 & Distal pull out \\
\hline 5 & 6 & 193.8 & 0 & 3.7 & 5.1 & 13.5 & 464 & Knot Failure \\
\hline 6 & 6 & 214.5 & 0 & 2.6 & 14.5 & 16.3 & 638 & Pull out jig \\
\hline 7 & 6 & 207.2 & 0 & 3.6 & 6.9 & 17.3 & 506 & Pull out jig \\
\hline Mean(SD) & & & $0.6(1.5)$ & $4.0(1.9)$ & $8.2(4.3)$ & $15.8(4.5)$ & $543(50)$ & \\
\hline 1 & 8 & 207.8 & 1.8 & 10.8 & 13.8 & 27.1 & 286 & Pull out jig \\
\hline 2 & 8 & 212.6 & 0 & 8.5 & 10.7 & 21.6 & 506 & Distal pull out \\
\hline 3 & 8 & 176.3 & 0 & 12.6 & 20.2 & Failed & & Knot failure \\
\hline 4 & 8 & 229.8 & 0 & 12.4 & 17.7 & Failed & & Knot failure \\
\hline 5 & 8 & 201.1 & 2.4 & 14.8 & 19.1 & 31.7 & 591 & Distal pull out \\
\hline 6 & 8 & 233.6 & 0 & 10.0 & 13.3 & 26.2 & 526 & Pull out jig \\
\hline Mean(SD) & & & $1.1(1.4)$ & $11.0(2.7)$ & $14.2(3.5)$ & $26.6(4.1)$ & $422(81)$ & \\
\hline
\end{tabular}

The Cross Sectional Area of the Ellipsoid tendons were determined using the formula: Area $=\pi \cdot A P$ radius $\cdot$ Transverse radius

Out of the 19 specimens tested, 7 of these resulted in pull out from the clamps holding the tendons before cyclical loading resulted in ultimate failure of the repair. Regression analysis reveals no significant $(p=0.32)$ difference between the ultimate strength of the 3 repair models ( 4 vs. $6: p=0.30,4$ vs. $8: p=0.87 ; 6$ vs. 8 : $p=0.39$ ). The mean ultimate tensile strengths (SEM) were for 4-strand $464.8 \mathrm{~N}$ (27.4), 6-strand $543.5 \mathrm{~N}$ (49.6), and 8-strand 422.1 N (80.5). In all specimens ultimate tensile failure occurred at separation far in excess of clinical failure.

The mode of failure was distal pull out in $41.7 \%$ of specimens, proximal pull out in $20.8 \%$ of specimens and knot failure in $33.3 \%$ of specimens. Knot failure occurred in two absorbable monofilament suture repairs and one of the 4 and 6 strand specimens. There was only one case (in a 4-strand repair), in which the suture snapped.

\section{Discussion}

The most important finding of this study was that repairs performed with non-absorbable braided sutures resulted in less separation than with absorbable monofilament sutures when subjected to a loading protocol.
The separation of tendon ends when subjected to 100 cycles of $100 \mathrm{~N}$ loads was less than $1 \mathrm{~cm}$ when specimens were repaired with the non-absorbable suture. When loads of $190 \mathrm{~N}$ were applied for 100 cycles, the non-absorbable repair models had $16.5 \mathrm{~mm}$ of separation whereas the absorbable suture repairs resulted in clinical failure $(\geq 20 \mathrm{~mm})$ or actual failure.

Although the two loading protocols are considered to be consistent with walking in a brace with a $2.5 \mathrm{~cm}$ heel raise and passive range of movement exercises, the quantitative separation reported in this study is not directly applicable to patients for number of reasons. Firstly the bovine tendons were larger than those found in patients, they did not have pre-existing degeneration (Józsa \& Kannus, 1997; Maffulli et al., 2011a) and technically an open repair rather than a percutaneous repair of the dissected specimens was performed. This study was to compare suture configuration inserted using a percutaneous/minimally invasive technique. The differing superficial soft tissues between human and bovine tendons necessitated that specimens were dissected free from superficial soft tissues. The sutures were subsequently placed as an open repair eliminating the 


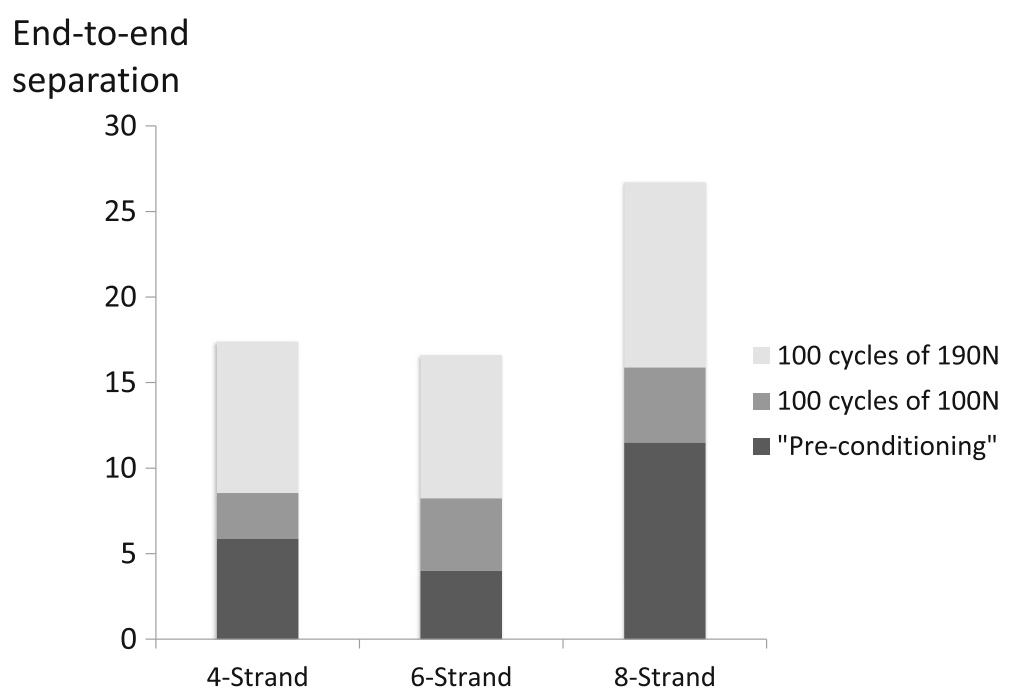

Fig. 3 Tendon separations during initial loading (10 N), and after 10 cycles of $100 \mathrm{~N}$ (preconditioning), 100 cycles of $100 \mathrm{~N}$ and 100 cycles of $190 \mathrm{~N}$

confounding variable of poor suture placement, which can occur in using a percutaneous placement (Demetracopoulos et al., 2014; Heitman et al., 2011). In Heitmann's series, 3/10 specimens had sutures, which passed superficial to the tendon when the Achillon jig was used to guide suture passage (Heitman et al., 2011). The favourable separation and failure characteristics of the 6-strand non-absorbable suture over the 8-strand absorbable suture shown in this study can, however, be applied to the management of Achilles tendon ruptures in patients.

Another finding of the study was the importance of "pre-conditioning" of the suture configuration prior to knot tying. In this study approximately half of the separation (68.6\% 4-strand, 48.5\% 6-strand and 72.7\% 8strand) occurred during the first 10 cycles of $100 \mathrm{~N}$ (Figs. 4b, 5b \& 6b), compared to the separation that had occurred by 100 cycles (Figs. 4c, 5c \& 6c). The aspect of pre-conditioning was highlighted in Clanton's study when $9.5 \mathrm{~mm} 77.9 \%$ of the overall $12.2 \mathrm{~mm}$ elongation occurred during the first 10 of 250 cyclic loading of 20-100 N (Clanton et al., 2015). By comparison when pre-conditioning was applied prior to knot tying Demetracopoulos found a 1000 cycles $20-100 \mathrm{~N}$ were required to produce $5 \mathrm{~mm}$ of separation in Achillon and PARS repairs (Demetracopoulos et al., 2014). It is recommended that pre-conditioning of at least 10 firms pulls are applied to the sutures in the proximal and distal tendon ends before the sutures are knotted during operative repair.

The use of the digital camera permitted the characteristics of failure to be observed and commented upon. With increased loading, usually in the loading to failure phase, the proximal tendon shortened slightly and appeared to bulk up as the suture tightened, the accordion effect (Figs. 4, 5 \& 6). In vivo, the consequences of this

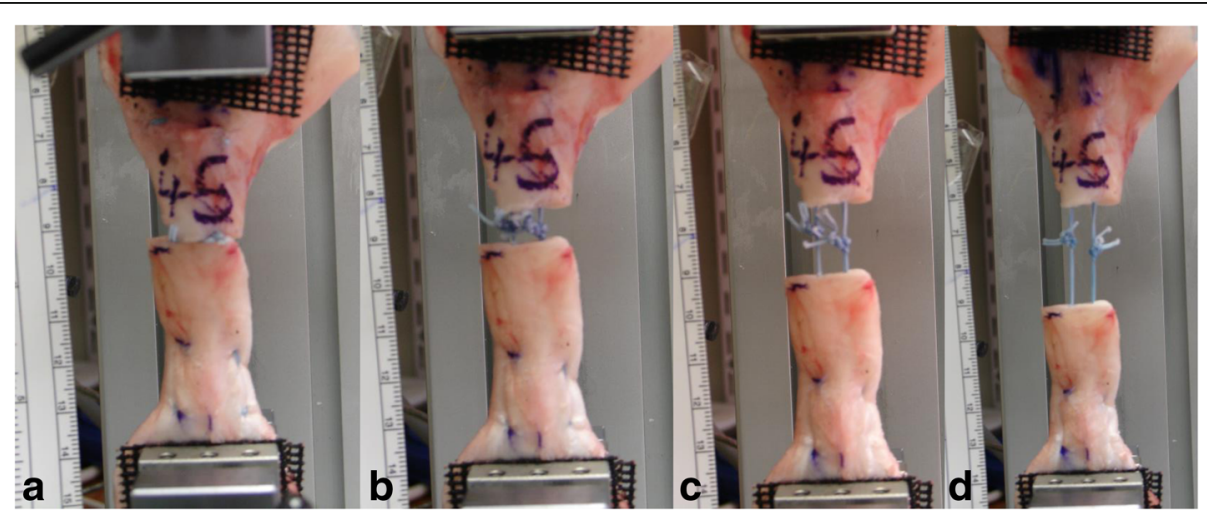

Fig. $4 \mathrm{~A}$ tendon specimen repaired with a non-absorbable suture during a initial loading $(10 \mathrm{~N})$ note the end to end apposition, and after b pre-conditioning (10 cycles of $100 \mathrm{~N}$ ), c 100 cycles of $100 \mathrm{~N}$ and $\mathbf{d} 100$ cycles of $190 \mathrm{~N}$ 


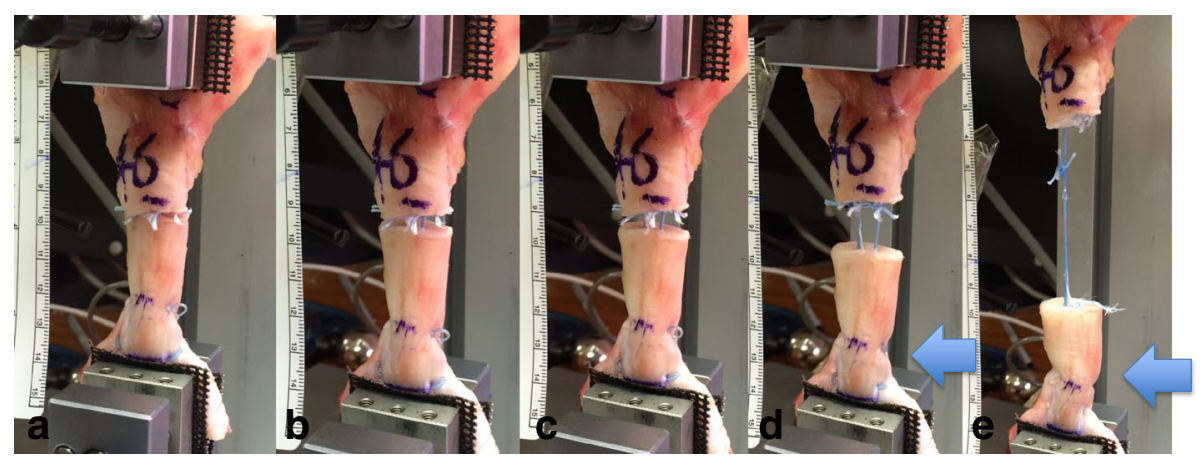

Fig. 5 The tendon specimen repaired with a non-absorbable suture during a initial loading (10 N), and after $\mathbf{b}$ pre-conditioning (10 cycles of $100 \mathrm{~N}$ ), c 100 cycles of $100 \mathrm{~N}$ and $\mathbf{d} 100$ cycles of $190 \mathrm{~N}$ demonstrating knot failure. e Ultimate tensile failure. Arrows indicate the reduction in length and increase in thickness related to the Bunnell suture termed the accordion effect

shortening effect may be minimized by pre-conditioning and then ensuring tendon end-to-end apposition with knots tied with the ankle placed in plantar flexion compared to the non-injured ankle. This operative "overtightening" compensates by subsequent elongation with loading, movement and remodeling (Heikkinen et al., 2016; Pajala et al., 2009; Schepull et al., 2012; Silbernagel et al., 2012). Another biomechanical property observed was that the absorbable sutures were notably more elastic than the non-absorbable sutures with more stretching and recoil rather than that observed with the stiffer nonabsorbable suture. This elastic nature of absorbable monofilament repair may be functionally beneficial in avoiding stress shielding of the repair although this must be considered against knot stability and pre-conditioning characteristics.
In terms of ultimate failure of the repair models, the 6-strand non-absorbable repair had the highest ultimate tensile failure. It is interesting to note that clinical failure, $\geq 20 \mathrm{~mm}$ of separation occurred in all specimens prior to ultimate tensile failure. Twenty millimeters of separation was chosen as this was the tendon lengthening noted to occur following non-operative treatment in Heikkinen's study (Heikkinen et al., 2017). Such lengthening would confer no advantage over operative treatment. The commonest mode of failure was distal pull-out of the Kessler suture in $41.7 \%$ of cases, in concert with other reported failure patterns (Longo et al., 2012). Thirty three percent of failure was due to knot failure and half of these $(n=2)$ occurred in the absorbable 8-strand suture. The tying of the 8-strand monofilament knots noticeably had greater friction than the PTFE coated braided sutures.

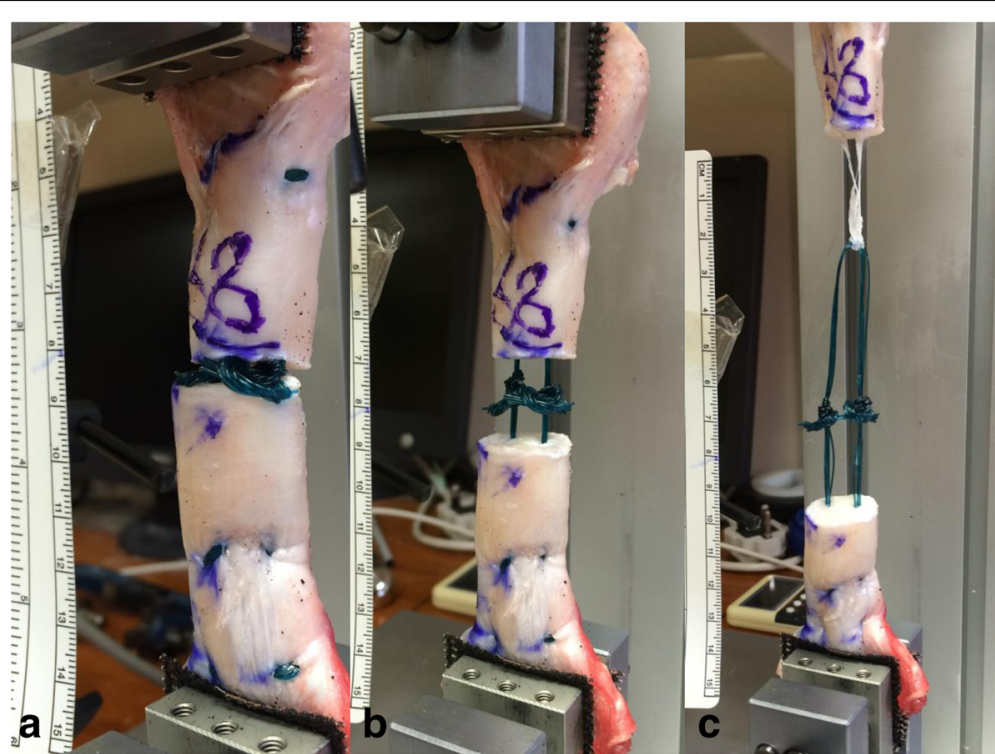

Fig. 6 A tendon specimen repaired with absorbable suture with a) initial loading, b) 100 cycles of $190 \mathrm{~N}$. Ultimate failure occurring by distal pull out with separation in excess of clinical failure (c) 
One hitch of absorbable suture was noted to untie during the loading sequence although knot failure occurred equally in absorbable and non-absorbable sutures. In vivo, the suture knots are surrounded by healing tendon end and so may be less prone to unraveling with movement at the 2-week time point.

There are a few limitations to this study although many of these relate to the tenotomy model common to many biomechanical aspects of Achilles tendon research.

The first is the problem of holding the specimens firmly in a clamp during the cyclical loading programme. Despite pilot testing to reduce tendon-clamp interface failure, loading of 7 out of the 19 specimens lead to pull out from the clamp. Four of these occurred at loads $\geq 400 \mathrm{~N}$, however, all had failed clinically ( $\geq 20 \mathrm{~mm}$ separation) by this point.

The use of a "clean" tenotomy, with a flat tendon end, may prevent shortening of the tendon at the time of repair due to the knots "within" the repair site. Artificial mop ends have been applied to tenotomy models (Backus et al., 2017; Grieco et al., 2015), which may permit shortening of the tendon by mop end-to-mop end apposition during repair and so subsequent separation with loading would restore normal length. In this model however, the flattened tendon ends permitted more accurate measurement of gapping measurement. The absence of a stable calcaneus may have also prevented pre-conditioning and the repair from being in as much tension as possible.

Suture placement in dissected tendons allowed optimal suture placement and clear looping of the suture outside the tendon. In vivo, the needle may pass down the same suture passage weakening the repair or even permit interposed fascia and paratenon layers forming adhesions reducing clinical outcome. Although monofilament is considered to slide through the tendon tissue more smoothly, it was considered to have greater friction between the strands than the PTFE coated braided suture. This may have reduced tension throughout the suture configuration and knot tightness.

This time zero model does not account for the healing of the tendon with time. It does, however, suggest that the repair may permit the maintenance of tendon tension during early loading whilst healing. The suture configurations tested were able to prevent gapping and excess lengthening; suggesting they are stable enough to allow early protected weight bearing on the metatarsal heads using a protective dorsal plantar flexion shell and axillary crutches and active movement exercises (Carmont \& Maffulli, 2008; Carmont et al., 2013; Carmont et al., 2015; Carmont et al., 2017). De La Fuente has recently demonstrated that functional braces should hold the ankle in $14^{\circ}$ plantar flexion to prevent failure (De La Fuente et al., 2016c). Clinically tendons repaired using these sutures and configurations did have an increase in Achilles Tendon Resting Angle (ATRA) following rehabilitation despite intra-operative shortening (Carmont et al., 2015; Carmont et al., 2017). At time zero an endto-end separation of greater than $4 \mathrm{~mm}$ (Ecker et al., 2016) and $1 \mathrm{~cm}$ (Hutchison et al., 2015) with passive flexion have been considered as indications for operative repair.

Further research is needed regarding the stability of early repair, avoidance of repair separation, tendon lengthening and yet the maintenance of elasticity to optimize resumption of biomechanical characteristics. The avoidance of tendon lengthening, the reduction in Achilles Tendon Resting Angle and the restoration of normal gastrocsoleus strength and Achilles tendon viscoelastic properties are important aspects is recovery from an Achilles tendon rupture. The pre-conditioning of sutures within the tendon ends, prior to knot tying is recommended to optimise repair tension and minimize tendon end-to-end separation.

\section{Conclusions}

The use of a non-absorbable suture resulted in less endto-end separation when compared to absorbable sutures when an Achilles tendon repair model was subject to cyclical loading. Ultimate failure occurred more commonly at the distal Kessler suture end although this occurred with separations in excess of clinical failure. The effect of early movement and loading on the Achilles tendon is not fully understood and requires more research.

\section{Acknowledgements \\ The authors would like to thank APB Foods, Shrewsbury and Arthrex ${ }^{\otimes}$ for their generous support for this research project. MRC has received a Research Bursary from the British Association of Sport and Exercise Medicine and is a member of Faculty on Arthrex Teaching courses. \\ Authors' contributions \\ MRC devised the study, performed the the repairs, the biomechanical analysis and wrote the paper. JHK performed the biomechanical analysis in conjunction with MRC, confirmed the statistical analysis and co-wrote the paper, KGS co-wrote the paper and is supervisor for MRC, JK co-wrote the paper and is a supervisor for MRC, KNH co-wrote the paper and is a super- visor for MRC. All Authors read and approved the final version of the manuscript.}

\section{Competing interests}

MRC is a member of Faculty on Arthrex Instructional Courses, otherwise the Authors declare there are no competing interests.

\section{Publisher's Note}

Springer Nature remains neutral with regard to jurisdictional claims in published maps and institutional affiliations.

\section{Author details}

'Department of Orthopaedic Surgery, Princess Royal Hospital, Shrewsbury \& Telford Hospital, Telford, UK. ²Department of Biomechanical Engineering, The Robert Jones \& Agnes Hunt District General Hospital, University of Keele, Keele, UK. ${ }^{3}$ Department of Physiotherapy, University of Delaware, Delaware, USA. ${ }^{4}$ Department of Orthopaedic Surgery, Sahlgrenska Academy, University 
of Gothenburg, Gothenburg, Sweden. ${ }^{5}$ Department of Orthopaedic Surgery, Kungsbacka Hospital, Kungsbacka, Sweden.

\section{Received: 28 May 2017 Accepted: 14 July 2017 \\ Published online: 21 July 2017}

\section{References}

Al-Mouazzen L, Rajakulendran K, Najefi A, Ahad N (2005) Percutaneous repair followed by accelerated rehablitation for acute Achilles tendon ruptures. J Orthop Surg (Hong Kong) 23(3):352-356 PMID: 26715717

Akizuki KH, Gartman EJ, Nisonson B, Ben-Avi S, McHugh MP (2001) The relative stress on the Achilles tendon during ambulation in an ankle immobiliser: implications for rehabilitation after Achilles tendon repair. Br J Sports Med 35(5):329-333 PMID: 11579067

Backus JD, Marchetti DC, Slette EL, Dahl KD, Turnbull TL, Clanton TO (2017) Effect of suture caliber and number of core strands on repair of acute Achilles ruptures: a biomechanical study. Foot Ankle Int 38(5):564-570 PMID: 28092968

Barfod KW, Sveen TM, Ganestam A, Ebskov LB, Troelsen A (2017) Severe functional disabilities after complications associated with acute Achilles tendon rupture with 9 years of follow up. J Foot Ankle Surg 56(3):440-444 PMID: 28216305

Benthien RA, Aronow MS, Doran-Diaz V, Sullivan RJ, Naujoks R, Adams DJ (2006) Cyclic loading of Achilles tendon repairs: a comparison of polyester and polyblend suture. Foot Ankle Int 27(7):512-518 PMID:1682718

Carmont MR, Maffulli N (2008) Modified percutaneous repair of the Achilles tendon. Knee Surg Sports Traumatol Arthrosc 16:199-203

Carmont MR, Silbernagel KG, Edge A, Mei-Dan O, Karlsson J, Maffulli N (2013) Functional outcome of Percutaneous Achilles repair. Orthop J Sports Med 1: 1. doi:10.1177/2325967113494584 PMID: 26535234

Carmont MR, Silbernagel KG, Brorsson A, Olsson N, Maffulli N, Karlsson J (2015) The Achilles tendon resting angle as an indirect measure of Achilles tendon length following rupture, repair and rehabilitation. Asia Pac J Sports Med Arthroscopy Rehabil Technol 2(2):49-55

Carmont MR, Silbernagel KG, Brorsson A, Olsson N, Maffulli N, Karlsson J (2017) The functional outcome of Achilles tendon minimally invasive repair using 4 and 6 strand non-absorbable suture: a cohort comparison study. Orthop J Sports Med [in press]

Clanton TO, Haytmanek CT, Williams BT, Civitarese DM, Turnbull TL, Massey MB, Wijdicks CA, LaPrade RF (2015) A biomechanical comparison of an open repair and 3 minimally invasive percutaneous Achilles tendon repair techniques during simulated progressive rehabilitation protocol. Am J Sports Med 43(8): 1957-1964 PMID: 26063402

Chan AP, Chan YY, Fong DT, Wong PY, Lam HY, Lo CK, Yung PS, Fung KY, Chan KM (2011) Clinical and biomechanical outcome of minimal invasive and open repairs of the Achilles tendon. Sports Med Arthrosc Rehabil Ther Technol 3(1):32

De La Fuente C, Peña y Lillo R, Carreño G, Marambio H (2016a) Prospective randomized clinical trial of aggressive rehabilitation after acute Achilles tendon ruptures repaired with Dresden technique. Foot (Edin) 26:15-22 PMID: 26802945

De La Fuente C, Carreño-Zillmann G, Marambio H, Henriquez H (2016b) Is the Dresden technique a mechanical design of choice suitable for the repair of middle third Achilles tendon ruptures? A biomechanical study. Rev Esp Cir Ortop Traumatol 60(5):279-285 PMID: 27435986

De La Fuente C, Carreño G, Soto M, Marambio H, Henriquez H (2016c) Clinical failure after Dresden repair of mid-substance Achilles tendon rupture: human cadaveric testing. Knee Surg Sports Traumatol Arthrosc [Epub ahead of print] PMID: 27256278

Del Buono A, Volpin A, Maffulli N (2014) Minimally invasive versus open surgery for acute Achilles tendon rupture:a systematic review. Br Med Bull 109:45-54 PMID: 24126569

Demetracopoulos CA, Gilbert SL, Young E, Baxter JR, Deland JT (2014) Limited open Achilles tendon repair using locking sutures versus non-locking sutures: an in-vitro model. Foot Ankle Int 35(6):612-618 PMID: 24651713

Ecker TM, Bremer AK, Krause FG, Müller T, Weber M (2016) Prospective use of a standardized non-operative early weight-bearing protocol for Achilles tendon rupture: 17 years of experience. Am J Sports Med 44(4):1004-1010 PMID: 26818449

Grieco PW, Frumberg DB, Weinberg M, Pivec R, Naziri Q, Uribe JA (2015) Biomechanical evaluation of varying the number of loops in a repair of a physiological model of Achilles tendon rupture. Foot Ankle Int 36(4):444-449
Guzzini M, Lanzetti RM, Prioetti L, Mazza D, Fabbri M, Monaco E, Ferri G, Ferretti A (2017) Interlocking horizontal mattress suture versus Kakiuchi technique in repair of Achilles tendon rupture: a biomechanical study. Doi: 10.1007/s10195-017-0455-x [Epub ahead of print] PMID: 28299456

Heikkinen J, Lantto I, Flinkkilä T, Ohtonen P, Pajala A, Siira P, Leppilahti J (2016) Augmented compared to non-augmented surgical repair after total Achilles rupture: results of a prospective randomized trial with 13 or more years of follow up. J Bone Joint Surg Am 98(2):85-92 PMID: 26791028

Heikkinen J, Lantto I, Flinkkila T, Ohtonen P, Niimaki J, Siira P, Laine V, Leppilahti J (2017) Soleus atrophy is common after non-surgical treatment of acute Achilles tendon ruptures: a randomized clinical trial comparing surgical and non-surgical functional treatments. Am J Sports Med 45(6):1395-1404

Heitman DE, Ng K, Crivello KM, Gallina J (2011) Biomechanical comparison of Achillon tendon repair system and the Krackow locking loop technique. Foot Ankle Int 32:879-887

Hockenbury RT, Johns JC (1990) A biomechanical in vitro comparison of open versus percutaneous repair of tendon Achilles. Foot Ankle 11(2):67-72

Horstmann T, Lukas C, Merk J, Bruaner T, Mündermann A (2012) Deficits 10 years after Achilles tendon repair. Int J Sports Med 33(6):474-479 PMID: 22499571

Hsu AR, Jones CP, Cohen BE, Davis WH, Ellington JK, Anderson RB (2015) Clinical outcomes and complications of percutaneous Achilles repair system versus open technique for acute Achilles tendon ruptures. Foot Ankle Int 36(11):1279-1286

Hutchison AM, Topliss C, Beard D, Evans RM, Williams P (2015) The treatment of a rupture of the Achilles tendon using a dedicated management programme. Bone Joint J 97-B(4):510-515

Józsa L, Kannus P (1997) Histopatholigcal findings in spontaneous tendon ruptures. Scand J Med Sci Sports 7(2):113-118 PMID:9211612

Keating JF, Will EM (2011) Operative versus non-operative treatment of acute rupture of tendo Achillis: a prospective randomised evaluation of functional outcome. J Bone Joint Surg Br 93(8):1071-1078 PMID:21768631

Keller A, Ortiz C, Wagner E, Wagner P, Mococain P (2014) Mini-open tenorrhaphy of acute Achilles tendon ruptures: medium-term follow-up of 100 cases. Am J Sports Med 42(3):731-736

Khan RJ, Carey Smith RL (2010) Surgical interventions for treating acute Achilles tendon ruptures. Cochrane Database Syst Rev 8(9):CD003674. doi:10.1002/ 14651858.CD003674 PMID: 20824836

Klein W, Lang DM, Saleh M (1991) The use of the Ma-Griffith technique for percutaneous repair of fresh ruptured tendon Achillis. Chir Organi Mov 76(3):223-228

Lee SJ, Sileo MJ, Kremenic IJ, Orishimo K, Ben-Avi S, Nicholas SJ, McHugh M (2009) Cyclic loading of 3 Achilles tendon repairs simulating early post operative forces. Am J Sports Med 37(4):786-790

Longo UG, Forriol F, Campi S, Maffulli N, Denaro V (2012) A biomechanical comparison of the primary stability of two minimally invasive techniques for repair of ruptured Achilles tendon. Knee Surg Sports Traumatol Arthrosc 20(7):1392-1397

Lantto I, Heikkinen J, Flinkkilä T, Ohtonen P, Kangas J, Siira P, Leppilahti J (2015) Early functional treatment versus cast immobilization in tension after Achilles rupture repair: results of a prospective randomized trial with 10 years or more of follow up. Am J Sports Med 43(9):2302-2309 PMID: 26229048

Lantto I, Heikkinen J, Flinkkilä T, Ohtonen P, Siira P, Laine V, Leppilahti J (2016) A prospective randomized trial comparing surgical and non-surgical treatments of acute Achilles tendon ruptures. Am J Sports Med 44(9):2406-2414

Ma G, Grifith TG (1977) Percutaneous repair of acute closed ruptured Achilles tendon: a new technique. Clin Orthop Relat Res 128:247-255

Maffulli N, Longo UG, Maffulli GD, Rabitti C, Khanna A, Denaro V (2011a) Marked pathological changes proximal and distal to the site if rupture in acute Achilles tendon ruptures. Knee Surg Sports Traumatol Arthrosc 19(4):680-687 PMID: 20563556

Maffulli N, Longo UG, Ronga M, Khanna A, Denaro V (2010) Favourable outcome of percutaneous repair of Achilles tendon ruptures in the elderly. Clin Orthop Relat Res 468(4):1039-1046 PMID: 19543777

Maffulli N, Longo UG, Maffulli GD, Khanna A, Denaro V (2011b) Achilles tendon ruptures in elite athletes. Foot Ankle Int 32(1):9-15 PMID: 21288429

Maffulli N, Longo UG, Maffulli GD, Khanna A, Denaro V (2011c) Achilles tendon ruptures in diabetic patients. Arch Orthop Trauma Surg 131(1):33-38 PMID: 20369360

Mavrodontidis A, Lykissas M, Koulouvaris P, Pafilas D, Kontogeorgakos V, Zalavras C (2015) Percutaneous repair of acute Achilles tendon rupture: a functional 
evaluation study with a minimum 10 year follow up. Acta Orthop Traumatol Turc 49(6):661-667 PMID: 26511694

McMahon SE, Smith TO, Hing CB (2011) A meta-analysis of randomise controlled trials comparing conventional to minimally invasive approaches for repair of an Achilles tendon rupture. Foot Ankle Surg 17(4):211-217 PMID: 22017889

Olsson N, Nilsson-Helander K, Karlsson J, Eriksson Bl, Thomée R, Faxén E,

Silbernagel KG (2011) Major functional deficits persist 2 years after acute Achilles tendon rupture. Knee Surg Sports Traumatol Arthrosc 19:1385-1393

Olsson N, Silbernagel KG, Eriksson BI, Sansone M, Brorsson A, Nilsson-Helander K, Karlsson J (2014) Stable surgical repair with accelerated rehabilitation versus nonsurgical treatment for acute Achilles tendon ruptures: a randomized controlled study. Am J Sports Med 41(12):2867-2876

Ortiz C, Wagner E, Mococain P, Labarca G, Keller A, Del Buono A, Maffulli N (2012) Biomechanical comparison of four methods of repair of the Achilles tendon: a laboratory study with bovine tendons. J Bone Joint Surg (Br) 94(5):663-667

Pajala A, Kangas J, Siira P, Ohtonen P, Leppilahti J (2009) Augmented compared with non-augmented surgical repair of a fresh total Achilles tendon rupture. A prospective randomised study. J Bone Joint Surg Am 91(5):1092-1100 PMID: 19411457

Schepull T, Kvist J, Aspenberg P (2012) Early E modulus of healing Achilles tendons correlates with late function: similar results with or without surgery. Scand J Med Sci Sports 22(1):18-23 PMID: 20673250

Silbernagel KG, Steele R, Manal K (2012) Deficits in heel rise height and Achilles tendon elongation occur in patients recovering from an Achilles tendon rupture. Am J Sports Med 40(7):1564-1571

Willits K, Amendola A, Bryant D, Mohtadi NG, Giffin JR, Fowler P, Kean CO, Kirkley A (2010) Operative versus non-operative treatment of acute Achilles tendon ruptures: a multicenter randomized trial using accelerated functional rehabilitation. J Bone Joint Surg Am 92:767-775 PMID: 21037028

Yang B, Liu Y, Kan S, Zhang D, Xu H, Liu F, Ning G, Feng S (2017) Outcomes and complications of percutaneous versus open repair of acute Achilles tendon rupture: a meta-analysis. Int J Surg 40:178-186 PMID:28288878

\section{Submit your manuscript to a SpringerOpen ${ }^{\circ}$ journal and benefit from:}

- Convenient online submission

- Rigorous peer review

- Open access: articles freely available online

- High visibility within the field

- Retaining the copyright to your article

Submit your next manuscript at $\gg$ springeropen.com 